\title{
The effect of solid fuel use on childhood mortality in Nigeria: evidence from the 2013 cross-sectional household survey
}

\author{
Osita Kingsley Ezeh ${ }^{1 *}$, Kingsley Emwinyore Agho², Michael John Dibley ${ }^{3}$, John Joseph Hall ${ }^{4}$ \\ and Andrew Nicolas Page ${ }^{2}$
}

\begin{abstract}
Background: In Nigeria, approximately $69 \%$ of households use solid fuels as their primary source of domestic energy for cooking. These fuels produce high levels of indoor air pollution. This study aimed to determine whether Nigerian children residing in households using solid fuels at $<5$ years of age were at higher risk of death.

Methods: The 2013 Nigeria Demographic and Health Survey data were analysed in Cox regression analyses to examine the effects of solid fuel use on deaths of children aged 0-28 days (neonatal), 1-11 months (post-neonatal), and 12-59 months (child).

Results: The results indicated that approximately $0.8 \%$ of neonatal deaths, $42.9 \%$ of post-neonatal deaths, and $36.3 \%$ of child deaths could be attributed to use of solid fuels. The multivariable analyses found that use of solid fuel was associated with post-neonatal mortality (hazard ratio $[\mathrm{HR}]=1.92,95 \%$ confidence interval [CI]: 1.42-2.58) and child mortality ( $H R=1.63, \mathrm{Cl}: 1.09-2.42)$, but was not associated with neonatal mortality ( $H R=1.01, \mathrm{Cl}: 0.73-1.26)$. Living in rural areas and poor households were associated with an increased risk of death during the three mortality periods.

Conclusion: Living in a rural area and poor households were strongly associated with an increased risk of a child $>1$ to $<60$ months dying due to use of solid fuels. The health effects of household use of solid fuels are a major public health threat that requires increased research and policy development efforts. Research should focus on populations in rural areas and low socioeconomic households so that child survival in Nigeria can be improved.
\end{abstract}

Keywords: Indoor air pollution, Solid fuels, Nigeria, Childhood mortality

\section{Background}

Indoor air pollution (IAP) emanating from burning solid fuels (wood, charcoal, animal dung, coal and crop waste) for cooking and home heating remains a major environmental and public health challenge in developing countries. Worldwide, approximately 4.3 million people have died as a result of illnesses attributed to IAP; these deaths include 534,000 children $<5$ years of age [1]. Most of the deaths occur in low- and middle-income countries, including Nigeria. However, the use of solid fuels and health effects of the mix of chemical components (e.g., carbon

\footnotetext{
* Correspondence: ezehosita@yahoo.com

'School of Medicine, University of Western Sydney, Locked Bag 1797, Penrith, NSW 2571, Australia

Full list of author information is available at the end of the article
}

monoxide, sulphur oxides, nitrogen oxides, particulates, benzene, formaldehyde, polyaromatic compounds, arsenic, lead) from solid fuel use [2,3] are not well understood even though household indoor cooking could result in high levels of these chemical components. Children $<5$ years of age are one of the vulnerable groups most likely to experience ill health caused by solid fuel use, as they are with their mothers whilst they are cooking [4].

Results of previous studies have indicated that children $<5$ years of age living in homes using solid fuels for cooking are at a greater risk of dying from acute respiratory illnesses $[5,6]$. Respiratory and immune system development occurs during this period, which may impair the immune response and lead to more severe infection 
and progression into the lower respiratory, particularly during the first year of life $[7,8]$. In 2014, the World Health Organization (WHO) indicated that $>50 \%$ of the deaths of children $<5$ years of age were attributed to acute lower respiratory infections triggered by solid fuels use [1]. Poverty is one of the main drivers for solid fuel use in many lowand middle-income countries.

Evidence from the Nigeria Demographic and Health Surveys (NDHS) indicated that in the past decade (from 2003-2013), the proportion of Nigerian households using solid fuels as their primary source of domestic energy for cooking remained constant at approximately $69 \%[9,10]$. Each year, over 95,000 Nigerians, including children $<5$ years of age, die from exposure to firewood smoke [11]. The health effects of household solid fuel use, and the increased risk of childhood mortality, have been somewhat neglected by public health researchers and policy makers in Nigeria.

We present new and emerging evidence on the effects of solid fuel use on childhood mortality in Nigeria. We examined the relationship between household solid fuel use and death rate of children $<5$ years for age groups (0-28 days, $1-11$ months, and 12-59 months) because the effects of environmental, demographic, and socioeconomic factors may be amongst these groups $[12,13]$.

\section{Methods}

The dataset used for this study was from the 2013 NDHS. The dataset is available online from ICF international, Rockville, MD, USA, after ethics approval is obtained [10]. The National Population Commission (NPC) conducts the NDHS in conjunction with ICF International. The United States Agency for International Development (USAID) is the main sponsor of the NDHS. Approximately every 5 years, the NDHS collects information on demographic and health issues (e.g., maternal and child health, childhood mortality, and education) from nationally representative households located in rural and urban areas. The 2013 NDHS data were obtained by interviewing eligible reproductive age women and men, aged 15-49 and 15-59 years, respectively, who participated in the household survey. The information obtained was recorded in three questionnaires (i.e., household, and women's and men's questionnaires). The detailed sampling procedures used in the NDHS have previously been published [10].

A total of 38,522 households were interviewed during the 2013 NDHS survey period. Of these households, 38,948 women and 17,359 men were successfully interviewed, corresponding to response rates of $97.6 \%$ and $95.2 \%$, respectively. A total of 30,726 singleton livebirths were reported for the 5-year period prior to the interview date. Multiple births were excluded from our analysis because compared with singletons, multiple births are associated with higher childhood mortality risk $[14,15]$. The analysis was restricted to births that occurred within the previous 5 years to minimise recall bias in the birth and death dates reported by the mothers. In addition, children $<5$ years of age are most likely to be indoors under their mother's supervision whilst cooking occurs.

\section{Descriptive study variables \\ Outcome variables}

The main outcome variables were neonatal mortality (death between birth and 28 days of age), post-neonatal mortality (death between 1 and 11 months of age) and child mortality (death between 12 and 59 months of age). Binary outcome variables were used in the analysis. Child death was considered a 'case' $(=1)$ if death occurred during the specified age period and a 'non-cases' $(=0)$ if the child was alive throughout the specified age period.

\section{Main study factor}

The main study factor was the main type of cooking fuels available to household members at the time of survey. The respondents were asked "What type of fuel does your household mainly use for cooking", which was followed by 11 categories of cooking fuels, including electricity, liquefied petroleum gas, natural gas, biogas, kerosene, coal/lignite, charcoal, wood, straw/shrubs/ grass, agricultural crop and animal dung. For the analysis, these 11 categories were classified into two groups based on NDHS definitions, solid (coal/lignite, charcoal, wood, straw/shrubs/grass, agricultural crop, animal dung) and non-solid (electricity, liquefied petroleum gas (LPG), natural gas, biogas, kerosene) fuels.

\section{Potential confounding variables}

The potential confounding variables considered were based on previous literature on the effects of cooking fuels on childhood mortality [16-18], particularly in developing countries. These variables were adapted to the data available in the 2013 NDHS. Potential child-related confounders were sex, mother's perception of her newborn's size at birth, and breastfeeding. The child's sex was also included in the analysis because results of a study in Bangladesh indicated that boys spend less time indoors compared with girls [19]. Therefore, girls are more likely to inhale IAP than boys, and girls are more likely than boys to be admitted for acute respiratory diseases [20]. The mother's perception of her newborn's size was categorised into two groups (small or very small, and average or large), and was used as a proxy for birth weight because $>50 \%$ of children are not weighed at birth [10]. Results of recent studies in India and Guatemala indicated that children born in households using high-polluting solid fuels were $73 \mathrm{~g}$ and $63 \mathrm{~g}$, 
respectively, lower in birth weight compared with children born in households using low-polluting fuels [21-23]. We considered breastfeeding in the analysis because it has a protective effect on the risk of respiratory disease [24,25], especially in the first year of an infant's life.

Confounders associated with maternal characteristics included education, working status and age at the birth of the child. Level of the mother's education is correlated with child survival, particularly during the post-neonatal and child period [26,27]. Compared with less educated mothers, educated mothers were more likely to obtain paid employment, which results in household members being exposed to solid and non-solid fuel combustion for shorter periods of time. Educated mothers can understand the health hazards of solid fuel use, and are more likely to purchase non-solid fuels. Educated mothers are also more likely to appropriately use healthcare services than their less educated peers. The level of education attained by mothers was categorised into three groups (no education, primary and secondary or higher education). Employment status was divided into two categories (working and not working). Mother's age at birth of the child was adjusted for because the frequency of exposure to cooking fuel smoke may vary as mothers grow older. It was categorised into four groups (age <20, 20-29, 30-39 and $40-49$ years).

The respondent's living location at the time of the survey was used to classify the residence, and was classified as urban or rural. More than two-thirds of households using solid fuels are in rural areas [10,28]. Household economic status is associated with use of high-polluting fuels [29]. As higher income levels are achieved, households are more likely to switch to more modern stoves and cleaner fuels, regardless of cultural traditions [30]. A household wealth index variable was constructed using household assets, which were weighted using a principal component analysis [31]. The assets considered were presence of a television, radio, refrigerator, telephone, car, bicycle, motorcycle and canoe, and ownership of agricultural land, a livestock farm or a bank account. In the NDHS data set, the household wealth variable was categorised into five quintiles: poorest, poorer, middle, richer, and richest. However, in the analysis the household wealth index was re-categorised into three groups. The bottom $40 \%$ of households was arbitrarily referred to as poor households, the next $40 \%$ as middle-income households, and the top $20 \%$ as high-income households.

Location of household kitchen was categorised into three groups (separate building, outdoor and in the house). However, frequency of cooking, ventilation facility, and duration of cooking variables were not included in this analysis because they were not collected. The previously mentioned potential confounding variables were used to measure the effects of use of solid fuels on neonatal, post-neonatal and child mortality.

\section{Statistical analysis}

Initially, mortality rates categorised by the two groups based on type of cooking fuel were estimated using a method similar to that described by Rutstien and Rojas [32]. Cox proportional hazards regression models were then used for multivariable analyses that independently examined the effect of each factor after adjusting for potential confounding variables.

A staged modelling technique was employed in the multivariable modelling. In the first stage, all potential confounding variables were entered into the baseline multivariable model to assess their relationship with the study outcomes. A stepwise backwards elimination process was performed, and variables that were associated with the study outcomes at a 5\% significance level were retained in the model (model 1). In the final stage of the analysis, the main study factor (type of cooking fuels) was entered into model 1 , and variables with a pvalue $<0.05$ were retained in the final model (model 2 ).

The hazard ratios (HRs) and their 95\% confidence intervals (CIs) obtained from the adjusted Cox proportional hazards models were used to measure the effect of the type of cooking fuels on neonatal, post-neonatal and child mortality. The "SVY" commands in STATA version 12.0 (Stata Corporation, College Station, TX, USA) were used in all analyses to adjust for the cluster sampling survey design, weights, and the calculation of standard errors.

The population attributable risk (PAR) was calculated to estimate total risk of neonatal, post-neonatal and child mortality in the general population that was attributable to household air pollution from smoke emanating from solid fuel use between 2009 and 2013. PAR was obtained using the following formula, which is recommended for multivariate-adjusted relative risks [33,34]:

$$
\begin{aligned}
P A R= & \text { proportion of deaths } \\
& \text { (neonatal, post-neonatal, and child }) \\
& \text { associated with using solid fuels for cooking, } \\
& X[(\text { aHR }-1) / a H R]
\end{aligned}
$$

where aHR was the adjusted hazard ratio for (neonatal, post-neonatal, and child) mortality from use of solid fuel.

\section{Results}

A weighted total of 30,726 singleton live-births of children occurred within the 5-year period prior to the 2013 NDHS survey interview date. Of the total live births, 2,615 children died within the 5-year period. These deaths consisted of 1,011 neonates (first day of life to 28 days of age), 789 post-neonates (between 1 and 
11 months of age), and 815 young children (between 12 and 59 months of age).

Table 1 presents the results for the percentage distribution of neonatal, post-neonatal, and young child deaths by selected background characteristics. In the 2013 NDHS, approximately $82 \%$ of neonates died in

Table 1 Percentage distribution of neonatal, post-neonatal and child mortality by background characteristics

\begin{tabular}{|c|c|c|c|}
\hline Variables & $\begin{array}{c}\text { Neonatal } \\
\text { deaths } \\
(n=1,011)\end{array}$ & $\begin{array}{c}\text { Post-neonatal } \\
\text { deaths } \\
(n=789)\end{array}$ & $\begin{array}{c}\text { Child deaths } \\
(n=815)\end{array}$ \\
\hline \multicolumn{4}{|l|}{ Residence type } \\
\hline Urban & 29.1 & 26.9 & 17.1 \\
\hline Rural & 70.9 & 73.1 & 82.9 \\
\hline \multicolumn{4}{|c|}{ Household wealth index } \\
\hline Poor & 52.2 & 60.6 & 71.2 \\
\hline Middle & 34.0 & 30.4 & 24.6 \\
\hline Rich & 13.8 & 9.0 & 4.2 \\
\hline \multicolumn{4}{|l|}{ Mother's education } \\
\hline No education & 52.1 & 59.8 & 69.2 \\
\hline Primary & 21.9 & 17.5 & 17.5 \\
\hline Secondary or higher & 25.9 & 22.7 & 13.3 \\
\hline \multicolumn{4}{|c|}{ Mother's working status* } \\
\hline Not working & 35.0 & 33.9 & 33.2 \\
\hline Working & 64.5 & 66.1 & 66.8 \\
\hline \multicolumn{4}{|l|}{ Mother's age } \\
\hline$<20$ & 7.9 & 7.1 & 4.8 \\
\hline $20-29$ & 47.4 & 44.8 & 46.1 \\
\hline $30-39$ & 33.3 & 36.3 & 36.7 \\
\hline $40-49$ & 11.4 & 11.8 & 12.4 \\
\hline \multicolumn{4}{|l|}{$\begin{array}{l}\text { Mother's perceived } \\
\text { baby size* }\end{array}$} \\
\hline Small or very small & 23.5 & 16.9 & 18.7 \\
\hline Average or larger & 68.2 & 76.9 & 76.0 \\
\hline \multicolumn{4}{|l|}{ Sex } \\
\hline Female & 42.6 & 49.0 & 48.7 \\
\hline Male & 57.4 & 51.0 & 51.3 \\
\hline \multicolumn{4}{|c|}{ Currently breastfeeding } \\
\hline Yes & 28.7 & 35.6 & 43.1 \\
\hline No & 71.3 & 64.4 & 56.9 \\
\hline \multicolumn{4}{|l|}{ Location of Kitchen* } \\
\hline Separate building & 17.6 & 19.7 & 16.1 \\
\hline Outdoor & 22.8 & 25.2 & 22.6 \\
\hline House & 59.3 & 54.3 & 61.2 \\
\hline \multicolumn{4}{|c|}{ Type of cooking fuel* } \\
\hline Solid fuel & 82.2 & 89.6 & 93.8 \\
\hline Non-solid fuel & 16.4 & 9.6 & 5.6 \\
\hline
\end{tabular}

*Percentages did not add up to $100 \%$ because of missing values. households using solid fuels for cooking. This number increased to $90 \%$ for the post-neonatal group and was $94 \%$ for the young child group. Wealthy households had the lowest percent of deaths compared with poor and middle-income households $(13.8 \%$ neonatal, $9.0 \%$ postneonatal, and $4.2 \%$ child). Greater than $70 \%$ of the neonatal, post-neonatal, and child deaths occurred in the rural areas.

The neonatal mortality rate (NMR) was higher among neonates born to mothers in households using solid fuels for cooking (NMR: 33.4 vs 29.6). The post-neonatal mortality rate (PMR) in households using solid fuels for cooking was greater than in households using non-solid fuels (PMR: 28.4 vs 13.6). Similarly, the child mortality rate (CMR) for children aged 12-59 months was higher in households using solid fuels for cooking compared with households not using solid fuels for cooking (CMR: 30.7 vs 8.2).

Approximately, $0.8 \%$ of neonatal deaths (PAR: 0.8; CI: $-7.8-2.8$ ), $43 \%$ of post-neonatal deaths (PAR: 42.9; CI: $31.9-61.4$ ) and $36 \%$ of child deaths (PAR: 36.3; CI: 33.1-52.1) for the 5-year period prior to the 2013 NDHS survey may be attributed to the use of solid fuels.

\section{The effect of solid fuel use on neonatal mortality}

Table 2 presents the results for the effect of cooking fuel on neonates survival after adjusting for potential confounding factors. Neonates born to mothers in households using solid fuels for cooking had a slightly higher risk of neonatal death $(\mathrm{HR}=1.01$; CI: $0.73-1.26)$ compared with neonates in households using non-solid fuel. This difference was not statistically significant.

Table 2 (model 2) presents the results for other significant factors that affected neonatal deaths. These factors were neonates born to mothers $<20$ years of age $(\mathrm{HR}=$ 3.16; CI: 2.12-4.74), neonates whose body size was perceived by the mother as small or smaller $(\mathrm{HR}=1.86$; $\mathrm{CI}$ : 1.55-2.24), male neonates ( $\mathrm{HR}=1.33$; CI: $1.13-1.64)$, neonates born to mothers residing in rural areas $(\mathrm{HR}=1.32$; CI: 1.06-1.64), and neonates not currently breastfed $(\mathrm{HR}=2.12$; CI: $1.75-2.55)$. When the place of residence was replaced by the household wealth index in the final model, children from poor households had a significantly high risk of infant death ( $\mathrm{HR}=1.55$; CI: 1.13-2.13).

\section{The effect of solid fuel use on post-neonatal mortality}

Table 3 presents the results for the effect of cooking fuel on post-neonatal mortality after adjustment for confounding factors. Compared with the reference category (Table 3, model 2), infants in households cooking with solid fuels ( $\mathrm{HR}=1.92$; CI: $1.42-2.58)$ had a significantly higher risk of post-neonatal mortality.

Model 2 (Table 3) revealed significant factors, other than households using solid fuels for cooking, that affected 
Table 2 Neonatal mortality model

\begin{tabular}{|c|c|c|c|}
\hline \multirow[t]{2}{*}{ Variables } & $(\text { Model } 0)^{n}$ & $($ Model 1)"' & $(\text { Model } 2)^{\wedge \sim}$ \\
\hline & HR $(95 \% \mathrm{Cl})$ & HR $(95 \% \mathrm{Cl})$ & HR (95\% Cl) \\
\hline \multicolumn{4}{|l|}{ Residence type } \\
\hline Urban & Ref & Ref & \\
\hline Rural & $1.36(1.13-1.65)$ & $1.30(1.07-1.58)$ & $1.32(1.06-1.64)$ \\
\hline \multicolumn{4}{|c|}{ Household wealth index } \\
\hline Rich & Ref & & \\
\hline Poor & 1.43(1.09-1.88) & & \\
\hline Middle & $1.14(0.86-1.52)$ & & \\
\hline \multicolumn{4}{|l|}{ Mother's education } \\
\hline Secondary or higher & Ref & & \\
\hline No education & $1.26(1.01-1.56)$ & & \\
\hline Primary & $1.20(0.94-1.52)$ & & \\
\hline \multicolumn{4}{|c|}{ Mother's working status } \\
\hline Not working & Ref & & \\
\hline Working & $0.76(0.64-0.91)$ & & \\
\hline \multicolumn{4}{|l|}{ Mother's age } \\
\hline $40-49$ & Ref & Ref & \\
\hline$<20$ & $3.14(2.09-4.70)$ & $3.17(2.12-4.74)$ & $3.16(2.12-4.74)$ \\
\hline $20-29$ & $1.11(0.81-1.51)$ & $1.22(0.90-1.66)$ & $1.220 .90-1.65)$ \\
\hline $30-39$ & $0.90(0.64-1.24)$ & $0.99(0.71-1.37)$ & $0.98(0.71-1.36)$ \\
\hline \multicolumn{4}{|c|}{ Mother's perceived baby size } \\
\hline Average or larger & Ref & Ref & Ref \\
\hline Small or very small & $1.95(1.63-2.34)$ & $1.86(1.55-2.24)$ & $1.86(1.55-2.24)$ \\
\hline \multicolumn{4}{|l|}{ Sex } \\
\hline Female & Ref & Ref & Ref \\
\hline Male & $1.31(1.11-1.55)$ & $1.33(1.13-1.57)$ & $1.33(1.13-1.64)$ \\
\hline \multicolumn{4}{|c|}{ Breastfeeding currently } \\
\hline Yes & Ref & Ref & Ref \\
\hline No & $1.98(1.64-2.38)$ & $2.12(1.76-2.55)$ & $2.12(1.75-2.55)$ \\
\hline \multicolumn{4}{|l|}{ Location of kitchen } \\
\hline Separate building & Ref & Ref & Ref \\
\hline Outdoors & $0.88(0.68-1.15)$ & & \\
\hline House & $1.15(0.92-1.44)$ & & \\
\hline \multicolumn{4}{|l|}{ Cooking fuel } \\
\hline Non-Solid fuel & Ref & & Ref \\
\hline Solid fuel & $1.16(0.91-1.47)$ & & $1.01(0.73-1.26)$ \\
\hline
\end{tabular}

${ }^{\wedge}$ Independent variables adjusted were: place of residence, wealth index, child size, child's gender, currently. Breastfeeding and mother's (education, working status, age); ${ }^{n}$ Model 0 - unadjusted independent variables; "'Model 1 - independent variables associated with neonatal mortality; Model 2 - Model 1 plus type of cooking fuels; Missing values were excluded from model 0,1 , and 2 .

post-neonatal deaths. There was a significantly higher risk of infant death for infants born to mothers residing in rural areas (HR $=1.16$; CI: $1.01-1.46)$, compared with infants in urban areas. When the place of residence was replaced by a household wealth index in the final model, infants born to mothers from poor households had a significantly high risk of infant death $(\mathrm{HR}=1.81$; CI: $1.15-$ 2.83). Infants born to mothers $<20$ years of age had a 3.63 times greater risk of dying compared with infants of mothers aged $\geq 20$ years ( $\mathrm{HR}=3.63$; CI: $2.41-5.46)$. There was a significantly higher risk of post-neonatal death for infants not currently breastfed (HR $=1.46$; CI: $1.22-1.74)$. 
Table 3 Post-neonatal mortality model

\begin{tabular}{|c|c|c|c|}
\hline \multirow[t]{2}{*}{ Variables } & $(\text { Model } 0)^{n}$ & $($ Model 1)"' & $\left(\right.$ Model 2) ${ }^{\wedge}$ \\
\hline & $\mathrm{HR}(95 \% \mathrm{Cl})$ & HR (95\% Cl) & HR $(95 \% \mathrm{Cl})$ \\
\hline \multicolumn{4}{|l|}{ Residence type } \\
\hline Urban & Ref & Ref & Ref \\
\hline Rural & $1.48(1.17-1.88)$ & $1.44(1.15-1.80)$ & $1.16(1.01-1.46)$ \\
\hline \multicolumn{4}{|c|}{ Household wealth index } \\
\hline Rich & Ref & & \\
\hline Poor & $2.48(1.78-3.45)$ & & \\
\hline Middle & $1.63(1.16-2.29)$ & & \\
\hline \multicolumn{4}{|l|}{ Mother's education } \\
\hline Secondary or higher & Ref & & \\
\hline No education & $1.51(1.20-1.91)$ & & \\
\hline Primary & $1.13(0.85-1.50)$ & & \\
\hline \multicolumn{4}{|c|}{ Mother's working status } \\
\hline Not working & Ref & & \\
\hline Working & $0.79(0.67-0.94)$ & & \\
\hline \multicolumn{4}{|l|}{ Mother's age } \\
\hline $40-49$ & Ref & Ref & \\
\hline$<20$ & $3.76(2.45-5.79)$ & $3.62(2.41-5.45)$ & $3.63(2.41-5.46)$ \\
\hline $20-29$ & $1.12(0.84-1.52)$ & $1.17(0.87-1.57)$ & $1.19(0.89-1.60)$ \\
\hline $30-39$ & $0.99(0.73-1.34)$ & $1.03(0.77-1.39)$ & $1.07(0.80-1.45)$ \\
\hline
\end{tabular}

Mother's perceived baby size

Average or larger

Ref

Small or very small

$1.28(1.04-1.59)$

Sex

Female

Ref

Male

$0.98(0.82-1.18)$

Breastfeeding currently

Yes

Ref

$1.38(1.14-1.67)$

Ref

Ref

1.41(1.18-1.69)

1.46(1.22-1.74)

Location of kitchen

Separate building

Ref

Outdoors

$0.92(0.69-1.22)$

House

$0.90(0.71-1.14)$

Cooking fuel

Non-solid fuel

Ref

Ref

$2.16(1.58-2.96)$

$1.92(1.42-2.58)$

^Independent variables adjusted were: place of residence, wealth index, child size, child's gender, currently breastfeeding and mother's (education, working status, age); ${ }^{n}$ Model 0 - unadjusted independent variables; "'Model 1 - independent variables associated with post-neonatal mortality; Model 2 - Model 1 plus type of cooking fuels; Missing values were excluded from model 0,1 and 2 .

The effect of solid fuel use on child mortality

Table 4 presents the results for the effect of cooking fuels on young children after adjustment for confounding factors. As indicated in model 2 results, children aged between 12 and 59 months and living in households using solid fuels for cooking had a greater risk of child mortality $(\mathrm{HR}=1.63 ; \mathrm{CI}: 1.09-2.42)$, compared with children in households using non-solid fuels.

There were other factors associated with a significantly higher risk of child mortality (Table 4, 
Table 4 Child mortality model

\begin{tabular}{|c|c|c|c|}
\hline \multirow[t]{2}{*}{ Variables } & $(\text { Model } 0)^{n}$ & $($ Model 1)"' & $(\text { Model } 2)^{\wedge \sim}$ \\
\hline & HR $(95 \% \mathrm{Cl})$ & HR $(95 \% \mathrm{Cl})$ & HR (95\% Cl) \\
\hline \multicolumn{4}{|l|}{ Residence type } \\
\hline Urban & Ref & Ref & Ref \\
\hline Rural & $2.45(1.95-3.07)$ & $1.75(1.39-2.22)$ & $1.59(1.25-2.03)$ \\
\hline \multicolumn{4}{|c|}{ Household wealth index } \\
\hline Rich & Ref & & \\
\hline Poor & $4.80(3.89-8.64)$ & & \\
\hline Middle & $2.52(1.64-3.88)$ & & \\
\hline \multicolumn{4}{|l|}{ Mother's education } \\
\hline Secondary or higher & Ref & Ref & Ref \\
\hline No education & $3.20(2.45-4.19)$ & $2.46(1.85-3.26)$ & $2.13(1.58-2.87)$ \\
\hline Primary & $1.99(1.46-2.73)$ & $1.74(1.26-2.39)$ & $1.55(1.12-2.15)$ \\
\hline
\end{tabular}

Mother's working status

Not working

Ref

Working

0.94(0.77-1.14)

Mother's age

40-49

Ref

$<20$

1.60(0.99-2.58)

20-29

$0.92(0.70-1.19)$

30-39

$0.88(0.67-1.16)$

Mother's perceived baby size

Average or larger

Ref

1.45(1.15-1.82)

Ref

1.06(0.89-1.26)

Ref

0.97(0.83-1.15)

No

Location of kitchen

Separate building

Outdoors

House

\section{Cooking fuel}

Non-solid fuel

Solid fuel

Independent variables adjusted were: place of residence, wealth index, child s

, child size, child's gender, currently breastfeeding and mother's (education, working status, cooking fuels; Missing values were excluded from model 0,1 , and 2.

model 2). Children had a significantly higher risk of death if their mothers had no formal education $(\mathrm{HR}=$ 2.13; CI: $1.58-2.87)$ or had a primary education $(\mathrm{HR}=$ 1.55; CI: 1.12-2.15). A significantly higher risk of death was also observed for children whose mothers resided in rural areas $(\mathrm{HR}=1.59 ; \mathrm{CI}: 1.25-2.03)$. When the place of residence was replaced by the household wealth index in the final model, children from poor households had a significantly high risk of child death $(\mathrm{HR}=3.73$; CI: 2.07-6.73). 


\section{Discussion}

Household use of solid fuels was associated with an increased risk of neonatal, post-neonatal and child mortality after controlling for potential confounders including household wealth status, place of residence, mother's level of education, mother's perceived size of her child at birth, sex, breastfeeding, mother's age and mother's employment status. Household use of solid fuels was not significantly associated with neonatal mortality. These findings are consistent with the results of a study conducted in India, which indicated that the association between household use of solid fuels and neonatal mortality is not significant [35]. Explanations for the lack of association include contribution from biological factors, such as low birth weight and prematurity, and complications related to pregnancy and delivery [36], rather than household environmental health hazards. Breastfeeding, including exclusive breastfeeding, may also protect against the development of respiratory diseases $[25,37]$. The strong effect of breastfeeding observed during the neonatal and post-neonatal mortality periods examined in this study reaffirms the protective effects of breastfeeding on improving the growth, health, and survival of children $<5$ years of age.

The effect of household use of solid fuels on mortality increased significantly during the post-neonatal period. This may be attributable to the fact that infants in their first year of life are usually carried on their mother's back or stand beside their mother while she is cooking, thus exposing the infant to high concentrations of pollutants from solid fuel for considerable periods. This result is in line with observations from a case-control study performed in Gambia that found that there is a significantly higher risk of mortality from acute lower respiratory infection among children often carried on their mother's back during cooking [38]. This practice is common in sub-Saharan African countries, including in Nigeria. Close proximity to a pollution source and time spent in the vicinity is likely to increase the level of exposure to pollution, which may lead to adverse health problems [39]. We noted that household use of solid fuels increased the risk of death for post-neonates by $92 \%$, compared with a $63 \%$ increased risk for children between 12 and 59 months. Compared with the infancy period, the lower mortality risk reported during the child period could be linked to their relatively well-developed lungs and immune response to pathogens [40].

Findings from this study indicate that during all age periods, children $<5$ years residing in rural areas had a significantly higher risk of mortality compared with their peers in urban areas. This finding is supported by results from other studies $[41,42]$, which indicated that residence in rural areas is a strong predictor of mortality of children $<5$ years of age. Clear urban-rural differences in household use of solid fuel are apparent in many subSaharan African countries. More than two-thirds of rural dwellers rely exclusively on gathered wood, charcoal, animal dung, crop waste, and coal waste for domestic energy $[10,28]$. Socioeconomic status (e.g., poor households) is one of the major factors affecting solid fuel use [29]. The significant effect of economic status was also apparent in all three age groups when place of residence was replaced by household wealth index in the final model. This finding reaffirms that wealth has a positive effect on child survival. Limited access to cleaner energy (electricity, LPG, gas) may also hinder rural residents from using efficient cooking fuels. Only $34 \%$ of the rural residents in Nigeria have access to electricity [10].

In addition to solid fuel use, other factors that were significantly associated with an increased risk of neonatal, post-neonatal, and child mortality included the mother's perception of her newborn's size at birth (small or very small), sex (male neonate), maternal age ( $<20$ years), and mother's level of education (no education). These results are consistent with the results of previous studies that examined the effect of cooking fuels on childhood mortality $[18,23,41,43]$.

It is possible that the estimates we reported in our study may have been underestimated because of the following reasons. (1) Children aged between 1 and 4 years are more likely to move around, as a result they may be exposed to both household and ambient air pollution. (2) NDHS did not gather information about the history of cooking fuel use. This is imperative because previous study indicated that household income is a strong predictor for switching to cleaner fuels [30].

This study has some limitations. First, data on households that use a combination of solid and non-solid fuels were not available from the NDHS database, and misclassification of use of cooking fuels may have occurred. Results of a study performed in India revealed that households reporting kerosene as their primary fuel for domestic energy but that they frequently switched to solid fuels reported higher levels of exposure to household air pollution [44]. A second limitation was that causal effects could not be measured because the analyses were based on a retrospective cross-sectional study. The third limitation was that detailed health assessments of the child and mother were not available at the time of the survey. Finally, other important variables such as ventilation facility, duration of cooking, and frequency of cooking were not used in this analysis because they were not collected in the 2013 NDHS. Strengths of this study included that the indicators used for cooking fuels was based on WHO recommendations. Recall errors arising from dates of birth and death given by mothers interviewed during the survey were minimised by restricting the analyses to births within the 5-year period preceding 
the survey. Data used in this study were from a nationally representative survey, which had a $97.6 \%$ response rate.

\section{Conclusions}

Our analyses examined whether children $<5$ years of age residing in households using solid fuels were at higher risk of death. The results indicate that use of solid fuels increased the risk of post-neonatal and child deaths.

In addition to the effect of solid fuel use on childhood mortality, children from households in rural areas, children from poor households, children delivered by younger mothers $(<20$ years of age), children perceived by their mothers to have been smaller than average at birth, and children with illiterate mothers had a significantly higher risk of neonatal, post-neonatal and child mortality. Findings from this study indicate the need to create public awareness of the health risks of using solid fuel and to implement community-based domestic energy interventions. To improve child survival in Nigeria, these interventions should target rural and low socioeconomic status households.

\section{Abbreviations \\ IAP: Indoor air pollution; NDHS: Nigeria demographic and health survey; NPC: National population commission; WHO: World health organisation; LPG: Liquefied petroleum gas; HR: Hazard ratio; aHR: Adjusted hazard ratio; PAR: Population attributable risk; Cl: Confidence interval; NMR: Neonatal mortality rate; PMR: Post-neonatal mortality; CMR: Child mortality rate.}

\section{Competing interests}

The authors declare that they have no competing interests.

\section{Authors' contributions}

OKE and KEA were involved in the conception and design of this study. OKE performed the literature review and analysis and drafted the manuscript. KEA, MJD, JH, and ANP provided advice on interpretation and revised and edited the manuscript. All authors read and approved the manuscript.

\section{Acknowledgements}

This study was part of the first author's thesis for a doctoral dissertation with the School of Medicine at the University of Western Sydney, Australia. We are grateful to Measure DHS, ICF International, Rockville, MD, USA for providing the 2013 NDHS data for this analysis.

\section{Author details}

'School of Medicine, University of Western Sydney, Locked Bag 1797, Penrith, NSW 2571, Australia. ${ }^{2}$ School of Science and Health, University of Western Sydney, Locked Bag 1797, Penrith, NSW 2571, Australia. ${ }^{3}$ Sydney School of Public Health, Edward Ford Building (A27), University of Sydney, Sydney, NSW 2006, Australia. ${ }^{4}$ School of Medicine and Public Health, Faculty of Health, University of Newcastle, Callaghan, NSW 2308, Australia.

Received: 27 August 2014 Accepted: 28 November 2014 Published: 16 December 2014

\section{References}

1. WHO: Burden of disease from Household Air Pollution for 2012. http:// www.who.int/phe/health_topics/outdoorair/databases/ HAP_BoD_results_March2014.pdf.

2. Smith KR: Fuel combustion, air pollution exposure, and health: the situation in developing countries. Ann Rev Energy Environ 1993, 18:529-566.

3. Naeher LP, Brauer M, Lipsett M, Zelikoff JT, Simpson CD, Koenig JQ, Smith KR: Woodsmoke health effects: a review. Inhal Toxicol 2007, 19:67-106.

4. Salvi SS, Barnes PJ: Chronic obstructive pulmonary disease in nonsmokers. Lancet 2009, 374:733-743.
5. Smith KR, Smith KR, Samet JM, Romieu I, Bruce N: Indoor air pollution in developing countries and acute lower respiratory infections in children. Thorax 2000, 55:518-532.

6. Gajate-Garrido G: The impact of indoor air pollution on the incidence of life threatening respiratory illnesses: evidence from young children in Peru. J Dev Stud 2012, 49:500-515.

7. Braga AL, Saldiva PH, Pereira LA, Menezes JJ, Conceicao GM, Lin CA, Zanobetti A, Schwartz J, Dockery DW: Health effects of air pollution exposure on children and adolescents in Sao Paulo, Brazil. Pediatr Pulmonol 2001, 31:106-113.

8. Boy E, Bruce N, Smith KR, Hernandez R: Fuel efficiency of an improved wood-burning stove in rural Guatemala: implications for health, environment and development. Energy Sustain Dev 2000, 4:23-31.

9. National Population Commission, Federal Republic of Nigeria: Final report on Nigeria Demographic and Health Survey. Calverton, Maryland, USA: ORC Macro; 2003.

10. National Population Commission, Federal Republic of Nigeria: Final report on Nigeria Demographic and Health Survey. Rockville, Maryland, USA: ICF International; 2013

11. International Centre for Energy, Environment and Development (ICEED): Prospects of clean cookstoves, by stakeholders. http://www.iceednigeria. org/news/prospects-of-clean-cookstoves-by-stakeholders/.

12. Blum D, Feachem RG: Measuring the impact of water supply and sanitation investments on diarrhoeal diseases: problems of methodology. Int J Epidemiol 1983, 12:357-365.

13. Esrey SA, Habicht JP: Epidemiologic evidence for health benefits from improved water and sanitation in developing countries. Epidemiol Rev 1986, 8:117-128

14. Hong R: Effect of multiple birth on infant mortality in Bangladesh. J Paediatr Child Health 2006, 42:630-635.

15. Uthman OA, Uthman MB, Yahaya I: A population-based study of effect of multiple birth on infant mortality in Nigeria. BMC Pregnancy Childbirth 2008, 8:41.

16. Wichmann J, Voyi KV: Influence of cooking and heating fuel use on 1-59 month old mortality in South Africa. Matern Child Health J 2006, 10:553-561.

17. Khalequzzaman M, Kamijima M, Sakai K, Chowdhury NA, Hamajima N, Nakajima T: Indoor air pollution and its impact on children under five years old in Bangladesh. Indoor Air 2007, 17:297-304.

18. Rehfuess EA, Tzala L, Best N, Briggs DJ, Joffe M: Solid fuel use and cooking practices as a major risk factor for ALRI mortality among African children. J Epidemiol Community Health 2009, 63:887-892.

19. Dasgupta S, Huq M, Khaliquzzaman M, Pandey K, Wheeler D: Indoor air quality for poor families: new evidence from Bangladesh. Indoor Air 2006, 16:426-444

20. Mahalanbis D, Gupta S, Paul D, Gupta A, Lahiri M, Khaled M: Risk factors for pneumonia in infants and young children and the role of solid fuel for cooking: a case-control study. Epidemiol Infect 2002, 129:65-71.

21. Boy E, Bruce N, Delgado H: Birth weight and exposure to kitchen wood smoke during pregnancy in rural Guatemala. Environ Health Perspect 2002, 110:109-114.

22. Sreeramareddy C, Shidhaye R, Sathiakumar N: Association between biomass fuel use and maternal report of child size at birth - an analysis of 2005-06 India Demographic Health Survey data. BMC Public Health 2011, 11:403.

23. Rinne ST, Rodas EJ, Rinne ML, Simpson JM, Glickman LT: Use of biomass fuel is associated with infant mortality and child health in trend analysis. Am J Trop Med Hyg 2007, 76:585-591.

24. Cushing AH, Samet JM, Lambert WE, Skipper BJ, Hunt WC, Young SA, McLaren LC: Breastfeeding reduces risk of respiratory illness in infants. Am J Epidemiol 1998, 147:863-870.

25. Heinig MJ: Host defense benefits of breastfeeding for the infant: effect of breastfeeding duration and exclusivity. Pediatr Clin North Am 2001, 48:105-123.

26. Buor D: Mothers' education and childhood mortality in Ghana. Health Policy 2003, 64:297-309.

27. Das Gupta M: Death clustering, mothers' education and the determinants of child mortality in rural Punjab, India. Popul Stud 1990, 44:489-505.

28. WHO: Indoor smoke from solid fuels: Assessing the environmental burden of disease. http://www.who.int/quantifying_ehimpacts/ publications/9241591358/en/.

29. Larrea C, Kawachi I: Does economic inequality affect child malnutrition? The case of Ecuador. Soc Sci Med 2005, 60:165-178. 
30. Reddy AKN, Williams RH, Johansson TB, Baldwin S: Energy After Rio: Prospects and Challenges. In United Nations Development Programme in Collaboration with International Energy Initiative and Energy 21: United Nations Publications; 1997:1-176.

31. Deon F, Pritchett LH: Estimating wealth effects without expenditure data-or tears: an application to educational enrollments in states of India. Demography 2001, 38:115-132.

32. Rutstein SO, Rojas G: Guide to Demographic and Health Survey (DHS). Maryland: ORC Macro Calverton; 2006:93-102.

33. Rockhill B, Newman B, Weinberg C: Use and misuse of population attributable fractions. Am J Public Health 1998, 88:15-19.

34. Natarajan S, Lipsitz SR, Rimm E: A simple method of determining confidence intervals for population attributable risk from complex surveys. Stat Med 2007, 26(17):3229-3239.

35. Epstein MB, Bates MN, Arora NK, Balakrishnan K, Jack DW, Smith KR: Household fuels, low birth weight, and neonatal death in India: The separate impacts of biomass, kerosene, and coal. Int J Hyg Environ Health 2013, 216:523-532.

36. Jehan I, Harris H, Salat S, Zeb A, Mobeen N, Pasha O, McClure EM, Moore J, Wright LL, Goldenberg RL: Neonatal mortality, risk factors and causes: a prospective population-based cohort study in urban Pakistan. Bull World Health Organ 2009, 87:130-138.

37. Agho K, Dibley M, Odiase J, Ogbonmwan S: Determinants of exclusive breastfeeding in Nigeria. BMC Pregnancy Childbirth 2011, 11:2.

38. de Francisco A, Morris J, Hall AJ, Armstrong SJR, Greenwood BM: Risk factors for mortality from acute lower respiratory tract infections in young Gambian children. Int J Epidemiol 1993, 22:1174-1182.

39. Ezzati M, Saleh H, Kammen DM: The contributions of emissions and spatial microenvironments to exposure to indoor air pollution from biomass combustion in Kenya. Environ Health Perspect 2000, 108:833-839.

40. Jaspan HB, Lawn SD, Safrit JT, Bekker LG: The maturing immune system: implications for development and testing HIV-1 vaccines for children and adolescents. Aids 2006, 20:483-494.

41. Bassani DG, Jha P, Dhingra N, Kumar R: Child mortality from solid-fuel use in India: a nationally-representative case-control study. BMC Public Health 2010, 10:1-9.

42. Golding J, Greenwood R, McCaw-Binns A, Thomas P: Associations between social and environmental factors and perinatal mortality in Jamaica. Paediatr Perinat Epidemiol 1994, 8:17-39.

43. Pandey S, Lin Y: Adjusted effects of domestic violence, tobacco use, and indoor air pollution from use of solid fuel on child mortality. Matern Child Health J 2013, 17:1499-1507.

44. Balakrishnan K, Ramaswamy P, Sambandam S, Thangavel G, Ghosh S, Johnson P, Mukhopadhyay K, Venugopal V, Thanasekaraan V: Air pollution from household solid fuel combustion in India: an overview of exposure and health related information to inform health research priorities. Global Health Action 2011, 4:1-9.

doi:10.1186/1476-069X-13-113

Cite this article as: Ezeh et al:: The effect of solid fuel use on childhood mortality in Nigeria: evidence from the 2013 cross-sectional household survey. Environmental Health 2014 13:113.

\section{Submit your next manuscript to BioMed Central and take full advantage of:}

- Convenient online submission

- Thorough peer review

- No space constraints or color figure charges

- Immediate publication on acceptance

- Inclusion in PubMed, CAS, Scopus and Google Scholar

- Research which is freely available for redistribution 